\title{
The Coupling Effect of Lead and Polishing Treatments on the Passive Films of Alloy 690TT in High-Temperature and High-Pressure Water
}

\author{
Weipeng $\mathrm{Li}^{1}$, Jianying $\mathrm{He}^{2}$, Liqiu Guo ${ }^{3}$, Jinxu $\mathrm{Li}^{3}$ and Lijie Qiao ${ }^{1 *}$ \\ ${ }^{1}$ Beijing Advanced Innovation Center for Materials Genome Engineering, University of Science and Technology Beijing, \\ Beijing, China, ${ }^{2}$ Department of Structural Engineering, Faculty of Engineering, Norwegian University of Science and \\ Technology (NTNU), Trondheim, Norway, ${ }^{3}$ Corrosion and Protection Center, University of Science and Technology Beijing, \\ Beijing, China
}

OPEN ACCESS

Edited by:

Liujie Xu,

Henan University of Science and

Technology, China

Reviewed by:

Hanguang Fu,

Beijing University of Technology, China Jianjun Zhang,

Xihua University, China

Shengqiang $\mathrm{Ma}$,

X'an Jiaotong University

(XJTU), China

Xiaohui Zhi

Shijiazhuang Tiedao University, China

${ }^{*}$ Correspondence:

Lijie Qiao

lqiao@ustb.edu.cn

Specialty section:

This article was submitted to

Structural Materials,

a section of the journal

Frontiers in Materials

Received: 31 August 2019 Accepted: 08 November 2019 Published: 29 November 2019

Citation:

Li W, He J, Guo L, Li J and Qiao L (2019) The Coupling Effect of Lead and Polishing Treatments on the

Passive Films of Alloy 690TT in High-Temperature and High-Pressure

Water. Front. Mater. 6:300.

doi: 10.3389/fmats.2019.00300
In pressurized water reactors, the existence of lead contamination can promote the corrosion of Alloy 690TT. During the manufacturing, transportation, and assembly processes, Alloy 690TT surface is easily scratched and it is easily ignored. The effect of added lead on the scratched surface is different from that on the unscratched surface. In the present study, Alloy 690TT was treated with mechanical polishing (MP) and electrochemical polishing (EP) to generate scratched and unscratched surfaces. With the addition of lead, the thickness of passive film on the MP sample increases by eight times, while that on the EP sample only slightly increases. These chemical composition changes of passive films induced by lead result in the drop of their electrical resistivity, and the electrical resistivity of passive film on the MP sample is reduced by two orders of magnitude, while that on the EP sample decreases only three times. Nevertheless, the thickness and electrical resistivity of passive film on the MP sample are always greater than those of the EP sample. The toxic effect of lead on the MP sample is more severe than that of the EP sample, which may be closely related to their subsurface microstructure. Therefore, Alloy 690TT should better avoid being scratched in the secondary circuit system of pressurized water reactors, as scratched behavior will result in a faster corrosion rate of Alloy 690TT with the presence of lead.

Keywords: lead, Alloy 690TT, mechanical polishing, electrochemical polishing, passive film, electrical resistivity

\section{INTRODUCTION}

Heat transfer tubes, made of nickel-based alloy, are a key component in pressurized water reactors (PWRs), which are used to transfer heat from primary to secondary circuit water system. However, the heat transfer tubes are usually vulnerable to extreme operating environment, for instance, high temperature and high pressure, irradiation, and various harmful elements. Studies suggest that there are many ways to damage the heat transfer tubes, such as primary side stress corrosion cracking (PWSCC), secondary side stress corrosion cracking (SCC), and intergranular corrosion (IGA) (Staehle and Gorman, 2003). These types of corrosions are usually closely related to 
abnormal surface conditions such as scratches produced during manufacturing, transportation, or assembly process. Meng et al. (2011) points out that the scratches increase the anodic current density of Alloy 690TT compared with electro-polished Alloy 690TT. The electrochemical reactivity of nano-grained scratch grooves is higher than that of scratch banks, so the scratch grooves are oxidized preferentially. The cracks initiate at the lip bands, scratch-banks, or scratch-bed in alkaline water containing lead at $330^{\circ} \mathrm{C}$ (Meng et al., 2009). Zhang proposes that MP treatment can accelerate the SCC initiation and propagation of Alloy 690TT in wt.\% $\mathrm{NaOH}$ solution (containing $100 \mathrm{mg} / \mathrm{L}$ litharge) compared with the electrochemical polishing (EP) treatment (Zhang et al., 2012). During the EP process, the surface mechanical stress layer is removed, and thus EP metal has a less defective and strain-free subsurface microstructure (Wang et al., 2017). The scratching, mechanical polishing (MP) and grinding treatments cause metal to have a high-stress layer with many sub-grains and dislocations on the surface (Meng et al., 2011; Zhang et al., 2011; Wang et al., 2017). Thus, subsurface microstructures with higher grain boundary and dislocation densities will result in higher corrosion rates.

In the secondary circuit system, lead is always inevitably introduced. The study shows that lead is the most harmful element for secondary side SCC (Staehle and Gorman, 2003). The fracture mode of lead-induced stress corrosion cracking (PbSCC) of 690TT alloy can be both transgranular and intergranular, which is closely related to the microstructures of 690TT alloy (Hwang et al., 2007, 2008). It has been found that lead-induced decrease of spinel oxide content in the passive film results in a lower film rupture ductility (Lu et al., 2008). After the passive film is ruptured, pitting corrosion initiates easily and SCC occurs in the Alloy 690 with the presence of stress (Hou et al., $2017 b)$. Therefore, lead-induced degradation of the passive film on nickel-based alloy is the key to PbSCC. In lead-containing solutions, lead blocks the dehydration process of hydroxides in the passive film and prevents oxygen from coming into the passive film, resulting in the decrease of the protective spinel oxides (Peng et al., 2008; Li et al., 2018). Thus, the passive film on nickel-based alloy in lead-containing solution becomes less protective due to the presence of lead. Moreover, lead not only penetrates into the passive film, but is also found in the crack paths (Persaud et al., 2018). In other words, lead not only causes the changes of passive film's chemical structure and an increased SCC susceptibility, but also participates in the growth of passive film and facilitates the propagation of cracks. However, it is still unclear whether lead has different effects on the growth of passive films formed on the Alloy 690TT surface with MP and EP treatments.
In the present study, Alloy 690TT samples with MP and EP treatments are pre-passivated at $270^{\circ} \mathrm{C}$ and 5.2-5.7 $\mathrm{MPa}$ for $24 \mathrm{~h}$ at open circuit potential in the pure water without and with $1 \mathrm{ppm} \mathrm{PbO}$. The electrical behavior and chemical composition of passive films formed on both the mechanically polished and electrochemically polished Alloy 690TT samples are examined by using current sensing atomic force microscopy (CS-AFM) and auger electron spectroscopy (AES), respectively. The mechanism of lead-induced changes of passive films formed on the Alloy 690TT with MP and EP treatments is revealed and discussed.

\section{EXPERIMENTS}

\section{Material Sample Preparation}

Tubes made of Alloy 690 were used in the present work, and its chemical composition is shown in Table 1. The alloy was solution annealed at $1,100^{\circ} \mathrm{C}$ for $5 \mathrm{~min}$ and then aged at $750^{\circ} \mathrm{C}$ for $10 \mathrm{~h}$. Then, continuous and semi-continuous intergranular carbides were obtained, which can enhance the SCC resistance of Alloy 600 and Alloy 690 in some environments (Airey, 1979; Kuang and Was, 2015). The treated 690 alloy was named Alloy 690TT. Alloy 690TT is an austenitic structure with a high density of annealing twins and a low amount of randomly distributed TiN inclusions (Hou et al., 2017a). The tube was $5 \mathrm{~mm}$ long and $19 \mathrm{~mm}$ in outer diameter with a wall thickness of $1.08 \mathrm{~mm}$. The samples were divided into two groups. One group of samples was wet ground with $\mathrm{SiC}$ paper up to $\# 5,000$, and then mechanically polished using $1 \mu \mathrm{m}$ diamond paste. After the other one was mechanically polished firstly, it was electrochemically polished in a mixed solution of $\mathrm{HNO}_{3}$ and $\mathrm{CH}_{3} \mathrm{OH}$ (the ratio of $\mathrm{HNO}_{3}$ and $\mathrm{CH}_{3} \mathrm{OH}$ is 3:7 in the solution) for $30 \mathrm{~s}$ at an applied voltage of $1.5 \mathrm{~V}$. All samples were cleaned in ethanol and de-ionized water and dried with air sequentially. The mechanically polished sample has a highstress layer with many sub-grains and dislocations on the surface (Wang et al., 2017). During the EP process, the surface mechanical stress layer is removed, and the electrochemically polished sample has a less defective and strain-free subsurface microstructure (Wang et al., 2017).

For most PWR nuclear power plants, the heat transfer tube operates at $230-290^{\circ} \mathrm{C}$ and $5-7 \mathrm{MPa}$ in a secondary circuit system. Therefore, two groups of samples were pre-passivated at $270^{\circ} \mathrm{C}$ and 5.2-5.7 $\mathrm{MPa}$ for $24 \mathrm{~h}$ at open circuit potential in pure water without and with $1 \mathrm{ppm} \mathrm{PbO}$. The autoclave made of 316 stainless steel was used in the present work. The $\mathrm{pH}$ values of solution without and with $1 \mathrm{ppm} \mathrm{PbO}$ at $270^{\circ} \mathrm{C}$ were 6.27 and 6.54 , respectively. Before passivation, the solution was deaerated using 4-5 $\mathrm{MPa}$ high-purity argon for $1 \mathrm{~h}$ at room temperature. After passivation, the specimens were cleaned in ethanol and de-ionized water, and dried with air.

TABLE 1 | The chemical compositions of Alloy 690 used in the present work (wt.\%).

\begin{tabular}{|c|c|c|c|c|c|c|c|c|c|c|c|c|c|c|}
\hline $\mathrm{Ni}$ & $\mathrm{Cr}$ & $\mathrm{Fe}$ & $\mathrm{Si}$ & $\mathrm{Mn}$ & $S$ & $P$ & C & $\mathrm{Al}$ & $\mathrm{Ti}$ & $\mathrm{Cu}$ & $\mathrm{Nb}$ & $B$ & Co & $\mathrm{N}$ \\
\hline 58.64 & 30.47 & 9.97 & 0.21 & 0.14 & 0.001 & 0.007 & 0.02 & 0.24 & 0.27 & 0.01 & 0.01 & 0.001 & 0.012 & 0.027 \\
\hline
\end{tabular}




\section{Passive Film Characterization}

The chemical composition of the prepared passive film was evaluated by AES using a PHI-700 produced by ULVAC-PHI Inc. Electron beam was emitted from a coaxial electron gun with an incident angle of $30^{\circ}$ relative to the sample surface. The high pressure of the electron gun was $5 \mathrm{KV}$. CMA energy analyzer was used, and the energy resolution was $1 \%$. Analysis chamber vacuum was controlled below $3.9 \times 10^{-9}$ Torr. Depth profiling was conducted over electron beam spot with a diameter of 100 $\mu \mathrm{m}$ under Ar-ion sputtering, and the sputter rate was $3 \mathrm{~nm} / \mathrm{min}$ based on calibration using a thermal oxidation $\mathrm{SiO}_{2}$.

The localized electrical behaviors of the prepared passive film were characterized by CSAFM using an Agilent 5500 system (Agilent Technologies, USA). All measurements were conducted in air at room temperature. The copper wires were attached to the side of the sample as the bottom electrode, and then they were connected to the system. The scanning probes acted as a top electrode over the sample. System parameters were kept the same for all measurements. The probe was conductive Pt-coated silicon tip with elastic constant $5 \mathrm{~N} / \mathrm{m}$. Deflection was set to $1.75 \mathrm{~V}$, tip bias was $3 \mathrm{~V}$, and the scanning area was all $20 \times 20 \mu \mathrm{m}$.

\section{RESULTS AND DISCUSSION}

\section{AES Analysis}

The chemical composition of passive film grown on Alloy 690TT with different conditions is evaluated by AES, and the results are plotted in Figure 1. It can be found that the outer layer of passive film is always a chromium-rich layer, except for the passive film grown on the MP sample in lead-containing solution. With the addition of lead, the outer layer of the passive film on the MP sample changes from chromium-rich to nickel-rich. The inner layer of the passive film is nickel-rich regardless of the presence of lead and the surface treatment of samples. With the help of lead, the oxygen content of the passive film on the MP sample greatly increases, while there is only a small increase in the passive film on the EP sample (Figure 2). As shown in Figure 3, lead has little effect on the atomic concentration of chromium in the passive film on the EP sample, while lead decreases the chromium content in the passive film on the MP sample. The nickel depth profiles are plotted in Figure 4. It is obvious that lead results in the decrease of the atomic concentrations of nickel inside the passive film on MP and EP samples. However, there is a slight increase for the atomic concentration of nickel in the skin layer of the passive film on the MP sample, which is attributed to the change of the chemical composition of outer layer particles (Figures 5a,e) induced by lead.

Lead is detected in the passive film (Figures 1B,D); however, the content of lead is not high in the passive film because the concentration of lead in the solution is low (only $1 \mathrm{ppm}$ ). It suggests that lead not only changes the chemical composition of the passive film, but also participates in the growth of the passive film. The relative thickness of the passive film is obtained on the basis of the standard $\mathrm{SiO}_{2}$ sputtering rate, and the thickness corresponding to half of the surface oxygen concentration is defined as the relative thickness of the passive film (Mischler et al., 2010). The relative thickness of the passive film on different samples without and with lead are obtained and shown in Table 2. When there is no lead in the passive film, the relative thickness of the passive film on MP sample is thicker than that on the EP sample. With the addition of lead, the relative thickness of passive film on the MP sample increases by eight times, whereas the relative thickness of the passive film on the EP sample only slightly increases. Thus, there is not much difference between the relative thickness of passive film on the EP sample with and without lead. This phenomenon may be related to the short passivation time of the EP sample and the small effect of lead on the relative thickness of the passive film on the EP sample. When the EP samples are pre-passivated for $168 \mathrm{~h}$ in high-temperature and high-pressure water, lead reduces the relative thickness of the passive film by half (Li et al., 2018).

\section{Localized Electrical Behaviors of the Passive Film}

The effect of lead on the surface topography and electric characteristics of the passive film for MP and EP samples is determined by CSAFM measurements, as shown in Figure 5. When lead is added to pure water at $270^{\circ} \mathrm{C}$ and $5.2-5.7 \mathrm{MPa}$, the surface topography of the passive films on MP and EP samples and their corresponding current characteristics are significantly different. As shown in Figure 5, the number of outer layer particles on the passive film on the MP sample is more than that on the EP sample. With the addition of lead, the amount of outer layer particles for both MP and EP samples decreases compared with lead-free samples, and the outer particles for EP samples nearly disappear. The leadinduced change of the passive film structures is similar to Kim's work using sodium hydroxide solutions (Kim et al., 2011). Although the amount of outer layer particles decreases for MP samples, the size of the particles is getting larger. With the presence of lead, the outer layer particles for the MP sample appear to contain more nickel atoms and less chromium atoms induced by lead.

In the lead-free passive films, the current signal is found only around the outer layer particles. In the lead-containing passive film, current peaks are detected on both sides of grain boundary for the EP sample. The regions of $\alpha$ and $\beta$ marked in the EP samples are selected, as shown in Figures $\mathbf{5 d}, \mathbf{h}$, and then the average current values in grain interior are calculated by Agilent processing software, as shown in Table 3. It can be seen that the introduction of lead clearly results in an increase of the current value in the matrix of the passive film. It means that the introduction of lead increases the defect in the matrix of the passive film according to Souier's work (Souier et al., 2010), including both sides of grain boundaries of the passive film grown on the EP sample.

The passive film grown on the metal can be considered as semiconductor film (Sikora et al., 1996; Schultze and Lohrengel, 2000), and its electrical properties can be characterized by electrical resistivity $\rho$ :

$$
\rho=V A / I d
$$



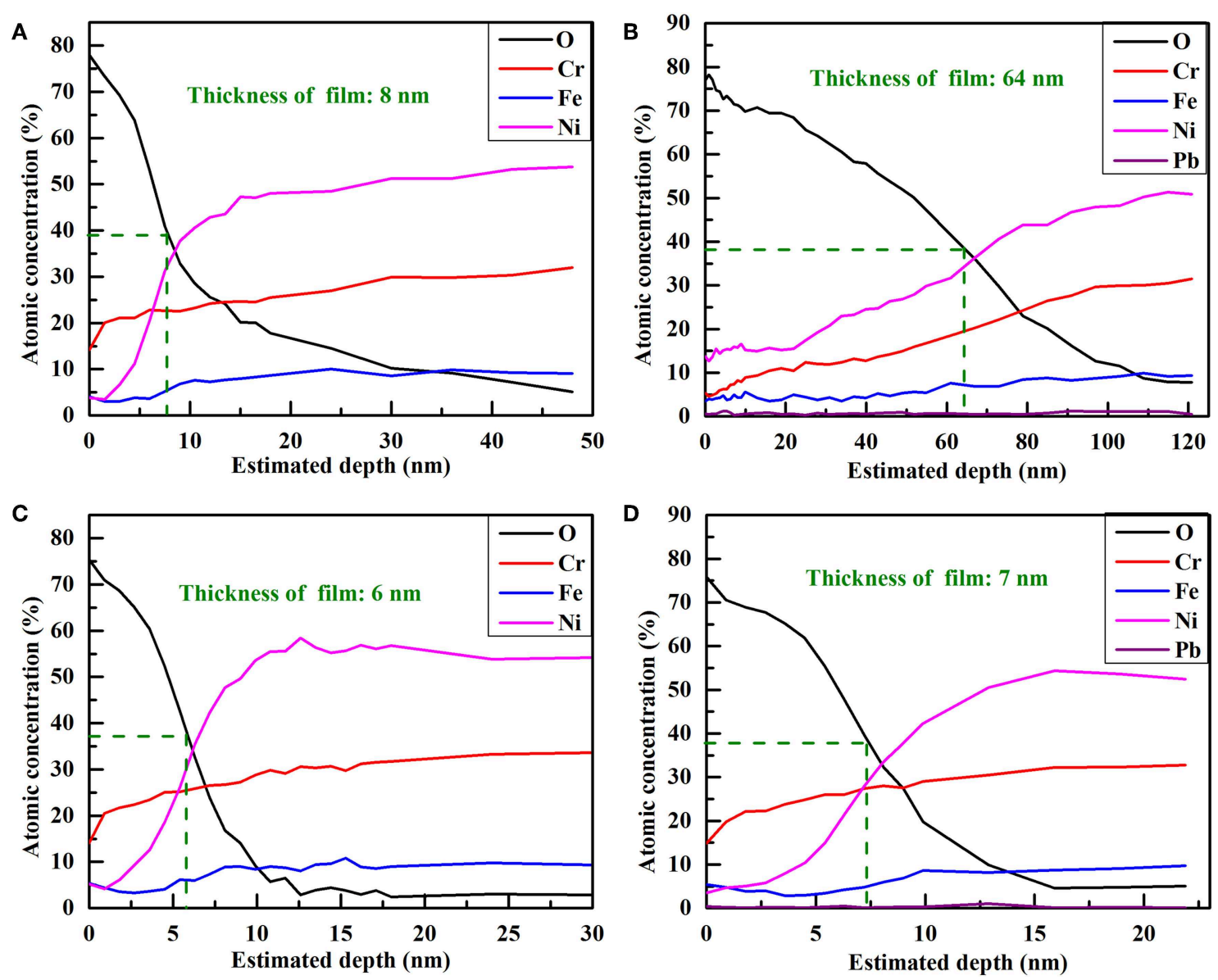

FIGURE 1 | The estimated depth profiles of the passive film passivated in high-temperature and high-pressure water for 24 h: (A) the MP sample without lead, (B) the MP sample with lead, (C) the EP sample without lead, (D) the EP sample with lead.
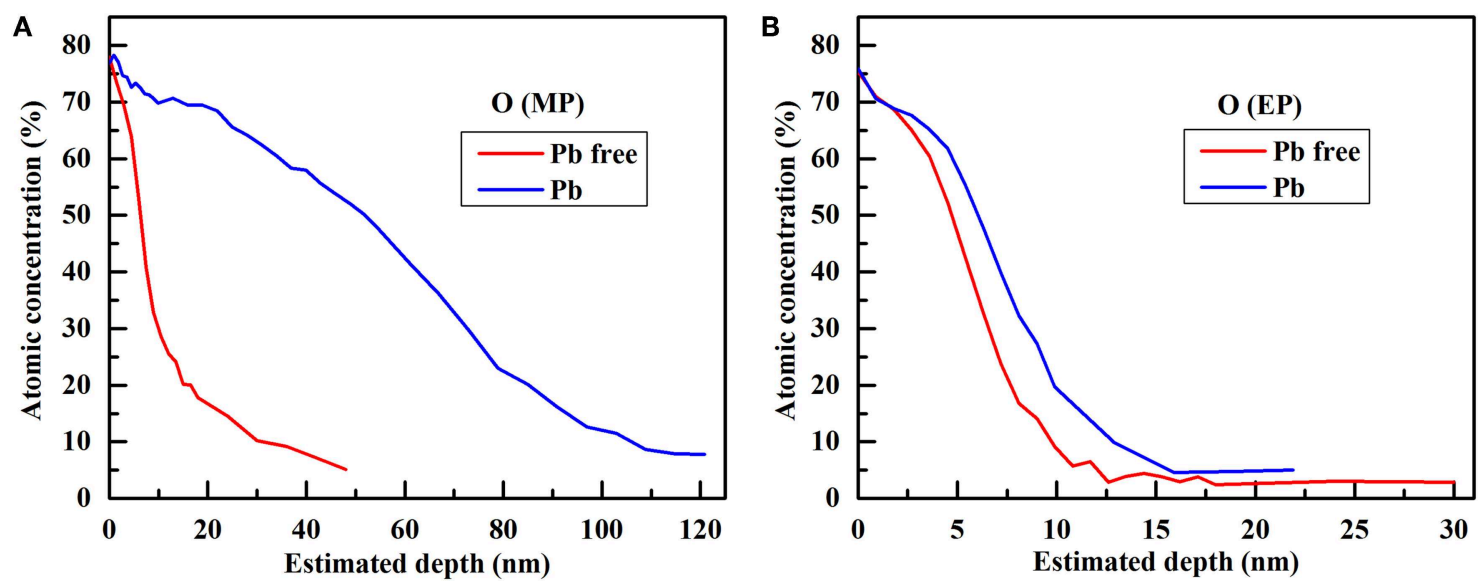

FIGURE 2 | Comparison of oxygen depth profiles in the passive film grown on different samples without and with lead: (A) MP sample, (B) EP sample.

where $V$ is tip bias, and the unit of $V$ is volts. $d$ is the relative thickness of the passive film, and the unit of $d$ is meter. $I$ is average current over a certain area, and the unit of $I$ is nanoampere. $A$ is the contact area between tip and sample, and the unit of
$A$ is square meters. The value of $A$ refers to our previous work (Li et al., 2018), and $3.0262 \times 10^{-17} \mathrm{~m}^{2}$ is taken. The electrical resistivity of the passive film on MP and EP samples with and without lead is shown in Table 4. Considering only the surface 

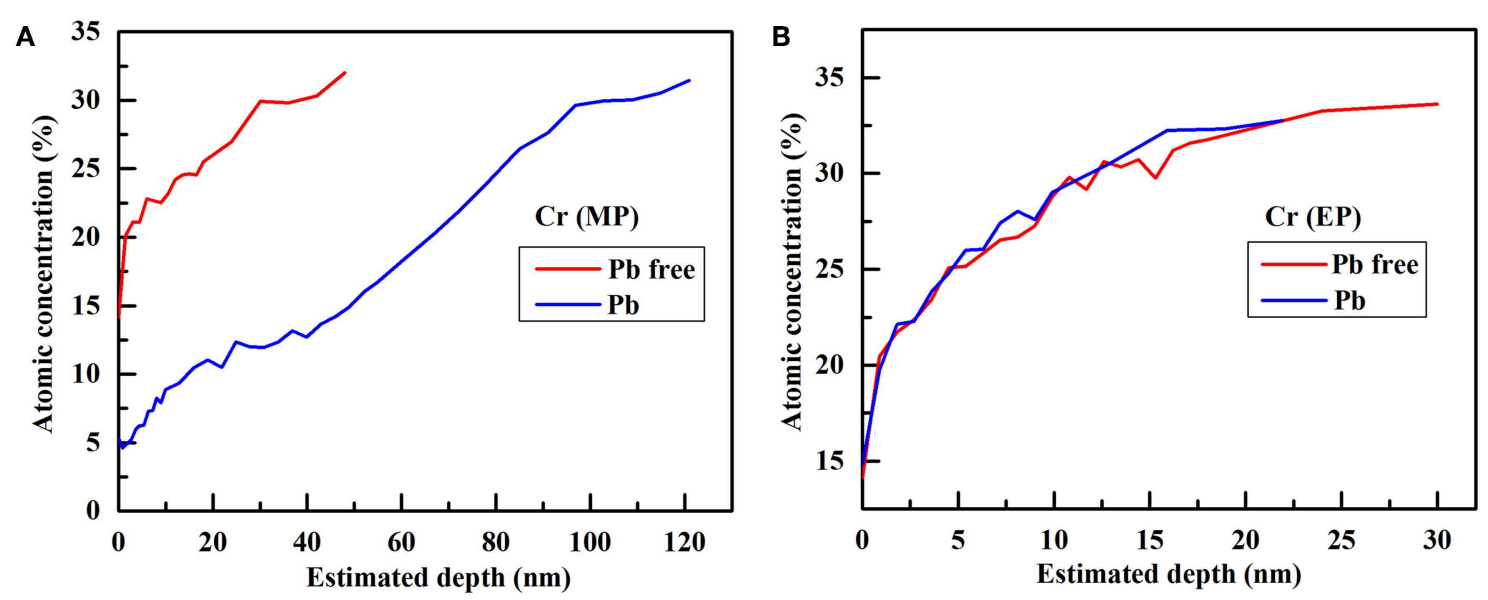

FIGURE 3 | Comparison of chromium depth profiles in the passive film grown on different samples without and with lead: (A) MP sample, (B) EP sample.
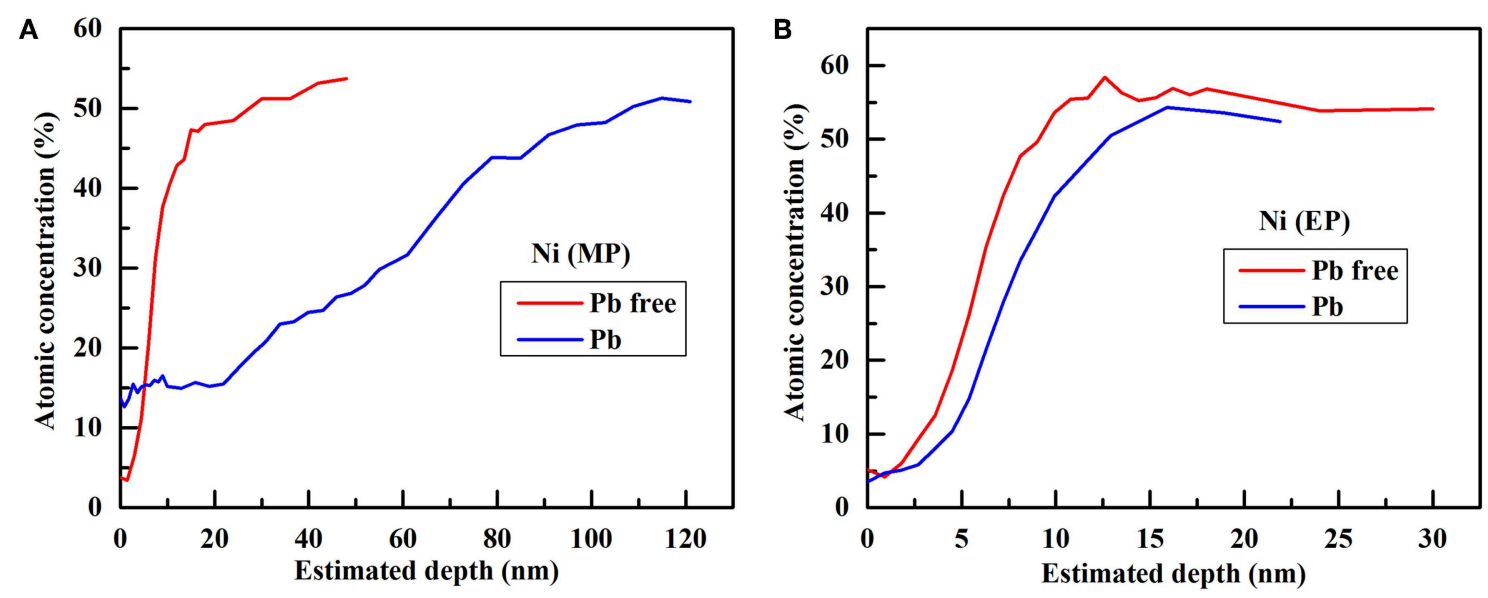

FIGURE 4 | Comparison of nickel depth profiles in the passive film grown on different samples without and with lead: (A) MP sample, (B) EP sample.

condition, the electrical resistivity of the passive film on the MP sample is much higher than that of the EP sample. Although the relative thickness of the passive film on the MP sample becomes thicker with the addition of lead, its electrical resistivity drastically decreases about 103 times. Due to the toxic effect of lead, the electrical resistivity of the passive films on the EP sample also decreases about three times.

\section{Effect of Lead and Surface Conditions on the Passive Film}

Many studies have shown that the growth of the inner layer and outer layer of the passive film is controlled by the inward diffusion of anion and outward diffusion of cation, respectively (Macdonald, 2011; Zhang et al., 2011; Payet et al., 2015). As the subsurface microstructure of metal can affect the internal diffusion of the anion, the growth of the passive film is closely related to the subsurface microstructure. The EP metal has a less defective and strain-free subsurface microstructure, and the MP metal has a high stress layer with many sub-grains and dislocations on the top of surface (Meng et al., 2011; Zhang et al., 2011; Wang et al., 2017). Therefore, the subsurface microstructures of the MP metal have a higher grain boundary and dislocation densities. Essentially no research has been conducted on the diffusion coefficient of oxygen along the grain boundaries in Alloy 690TT. Alloy 690TT is nickel-based, and thus it may be referred to the data of $\mathrm{Ni}$ proposed by Rebak and Szklarska-Smialowska (1996). The diffusion coefficient of oxygen along the grain boundaries is about $8.25 \times 10^{-11} \mathrm{~cm}^{2} / \mathrm{s}$ at $330^{\circ} \mathrm{C}$, which is very fast (Rebak and Szklarska-Smialowska, 1996). Marchetti et al. (2008) found that the diffusion coefficient of oxygen along the grain boundaries in the chromate-like oxide is much faster than the overall diffusion coefficient of the passive film on Alloy 690 at high temperature. Due to the high grain boundary densities, the diffusion of oxygen for the MP sample is faster and deeper, resulting in a faster growing and thicker passive film. 

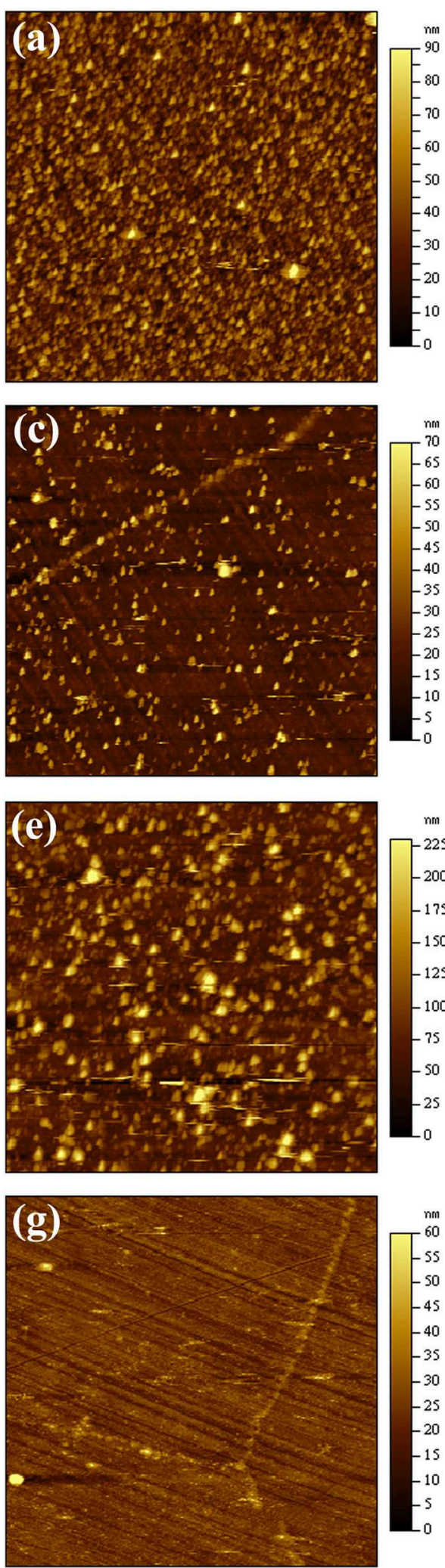
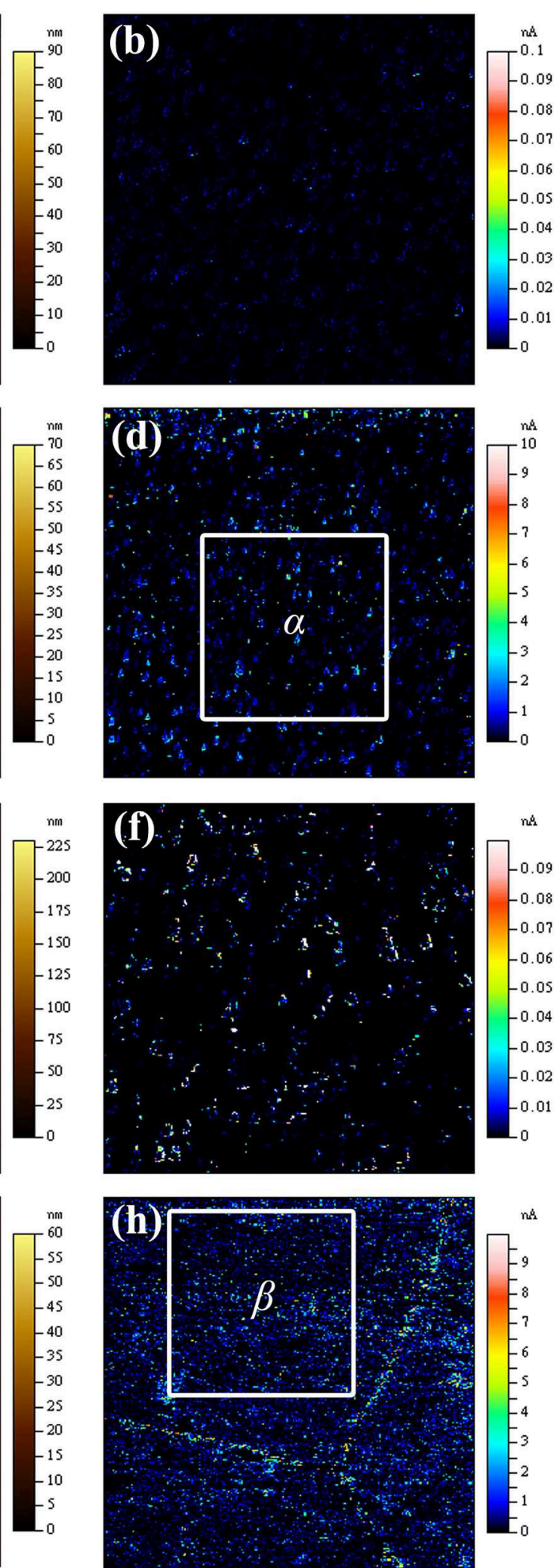

FIGURE 5 | AFM topography images and corresponding current images of the passive film on Alloy 690TT after EP and MP treatments passivated in high-temperature water for $24 \mathrm{~h}$ with and without 1 ppm lead: (a) a topography image of MP sample without lead; (b) a current image of MP sample without lead; (c) a topography image of EP sample without lead; (d) a current image of EP sample without lead; (e) a topography image of MP sample with 1 ppm lead; (f) a current image of MP sample with 1 ppm lead; (g) a topography image of EP sample with 1 ppm lead; (h) a current image of EP sample with 1 ppm lead. 
TABLE 2 | The relative thickness of the passive film on MP and EP samples with and without lead.

\begin{tabular}{lcc}
\hline Relative thickness of passive film $\boldsymbol{d}(\mathbf{n m})$ & MP sample & EP sample \\
\hline Lead-free & 8 & 6 \\
Lead & 64 & 7 \\
\hline
\end{tabular}

TABLE 3 | The average currents of the passive film on MP and EP samples with and without lead calculated by Agilent processing software.

\begin{tabular}{lll}
\hline Average current I (nA) & MP sample & EP sample \\
\hline Lead-free & $4.03 \times 10^{-4}$ & $1.47 \times 10^{-1}$ \\
Lead & $5.17 \times 10^{-3}$ & $3.29 \times 10^{-1}$ \\
\hline
\end{tabular}

TABLE 4 | The electrical resistivity $(\rho)$ of the passive film on MP and EP samples with and without lead

\begin{tabular}{lcc}
\hline Electrical resistivity $\boldsymbol{\rho}(\boldsymbol{\Omega} \cdot \boldsymbol{m})$ & MP sample & EP sample \\
\hline Lead-free & 28159.4 & 102.9 \\
Lead & 274.4 & 39.4 \\
\hline
\end{tabular}

Although lead is dissolved in solution, lead can enter the passive film in two ways (Lu et al., 2012). One way is to combine with cation vacancies at the interface between the solution and barrier layer of the passive film. The other one is the deposition of lead hydroxide, which may then dehydrate into oxyhydrogen compounds or oxides in the passive film. Many researches have shown that lead hinders the dehydration of hydroxides in the passive film, resulting in a decrease of oxide content ( $\mathrm{Lu}$ et al., 2008, 2012; Li et al., 2018). Therefore, the lead-containing passive film is less protective and is more prone to the inward diffusion of oxygen and the outward diffusion of chromium and nickel. Finally, lead results in an increase in oxygen concentration and a decrease in chromium and nickel concentrations in the passive film, but there is almost no change in the chromium content of the passive film on the EP sample.

Corrosion is an electrochemical process that is usually associated with electron transfer. Thus, the lower the electrical resistivity, the faster the corrosion process. As the electrical resistivity of the passive film on the MP sample without lead is much higher than that of the EP sample (Table 4), the passive film on the MP sample has a higher resistance to corrosion. With the addition of lead, the electrical resistivity of the passive film on the MP sample drops sharply, and the resistivity of the EP sample also decreases. Then, the protective properties of these passive films are getting worse, thus aggravating the corrosion of Alloy 690TT in high-temperature and high-pressure environments. For EP sample with the presence of lead, current peaks are detected on both sides of grain boundary carbides as shown in Figures $\mathbf{5 d , h}$. That is to say, the introduction of lead increases the defect on both sides of grain boundary carbides of the passive film grown on the EP sample according to Souier's work (Souier et al., 2010). Thus, Alloy 690TT is more susceptible to IGA due to the toxic effect of lead on both sides of grain boundary carbides for the EP sample. When there is stress or residual stress, Alloy 690TT may naturally undergo SCC. In the secondary circuit water system, the presence of lead can cause the failure of the heat transfer tube, which can result in safety accidents and huge economic losses. To protect the heat transfer tubes from the toxic effect of lead, lead should not be introduced into the secondary circuit water system of PWR.

\section{CONCLUSIONS}

The effect of lead on the passive film of Inconel 690TT alloy with MP and EP treatments in high-temperature and highpressure water has been investigated by AES and CS-AFM. The detrimental effect of lead on the composition structure and the electrical property of the passive film on Inconel 690TT alloy with MP and EP treatments has been analyzed and discussed. The following points can be drawn from the analyses:

(1) In lead-free environment, the relative thickness of the passive film on the mechanically polished sample is thicker than that of the electrochemically polished sample, and the electrical resistivity of the passive film on the MP sample is much higher than that of the EP sample. Therefore, the passive film on the MP sample is more resistant to corrosion than that on the EP sample in the lead-free environment.

(2) Compared with the lead-free passive film, the introduction of lead results in a more severe dissolution of chromium and nickel in the passive film on the MP sample, whereas lead only causes a slight decrease in the nickel content in the passive film on EP the sample.

(3) Lead increases the oxygen content in the passive film on MP and EP samples. The relative thickness of the passive film on the MP sample increases by eight times, while that on the EP sample only slightly increases.

(4) Lead reduces the electrical resistivity of the passive film of MP and EP samples. The MP sample shows the most severe decrease of electrical resistivity, while the electrical resistivity of the passive film on the EP sample decreases only about three times. Therefore, the toxic effect of lead on the MP sample is more severe than that of the EP sample.

\section{DATA AVAILABILITY STATEMENT}

All datasets generated for this study are included in the article/supplementary material.

\section{AUTHOR CONTRIBUTIONS}

WL: experiment operation, mechanism analysis, and writing this article. LQ: directing this article. JH: writing this article. LG: experimental analysis and writing this article. JL: experimental analysis.

\section{FUNDING}

This work was supported by the National Natural Science Foundation of China (Nos. 51431004, 51771031, and 51571030). 


\section{REFERENCES}

Airey, G. P. (1979). The effect of carbon content and thermal treatment on the SCC behavior of Inconel Alloy 600 steam generator tubing. Corrosion 35, 129-136. doi: 10.5006/0010-9312-35.3.129

Hou, Q., Liu, Z. Y., Li, C. T., and Li, X. G. (2017a). Effects of lead on oxidation behavior of Alloy 690TT within a high temperature aqueous environment. Appl. Surf. Sci. 426, 514-526. doi: 10.1016/j.apsusc.2017.07.201

Hou, Q., Liu, Z. Y., Li, C. T., and Li, X. G. (2017b). The mechanism of stress corrosion cracking of Alloy 690TT in a caustic solution containing lead. Corrosi. Sci. 128, 154-163. doi: 10.1016/j.corsci.2017.09.015

Hwang, S. S., Hong, P. K., Yun, S. L., Kim, J. S., and Thomas, L. (2007). Transgranular SCC mechanism of thermally treated alloy 600 in alkaline water containing lead. Corros. Sci. 49, 3797-3811. doi: 10.1016/j.corsci.2007.03.040

Hwang, S. S., Kim, D. J., Lim, Y. S., Kim, J. S., Park, J., and Kim, H. P. (2008). SCC mechanism of $\mathrm{Ni}$ base alloys in $\mathrm{Pb}$ contaminated water. Corrosi. Sci. Technol. 7, 189-193.

Kim, D. J., Kwon, H. C., Kim, H. W., Hwang, S. S., and Hong, P. K. (2011). Oxide properties and stress corrosion cracking behaviour for Alloy 600 in leaded caustic solutions at high temperature. Corros. Sci. 53, 1247-1253. doi: 10.1016/j.corsci.2010.12.016

Kuang, W., and Was, G. S. (2015). The effects of grain boundary carbide density and strain rate on the stress corrosion cracking behavior of cold rolled Alloy 690. Corrosi. Sci. 97, 107-114. doi: 10.1016/j.corsci.2015.04.020

Li, W. P., Mi, Z. S., Qin, S. X., Gao, L., He, J. Y., Guo, L. Q., et al. (2018). CS-AFM study on $\mathrm{Pb}$-induced degradation of passive film on nickel-based alloy in high temperature and high pressure water. Corrosi. Sci. 144, 249-257. doi: 10.1016/j.corsci.2018.08.054

Lu, B. T., Luo, J. L., and Lu, Y. C. (2008). Correlation between film rupture ductility and PbSCC of Alloy 800. Electrochim. Acta 53, 4122-4136. doi: $10.1016 /$ j.electacta.2007.12.070

Lu, B. T., Luo, J. L., and Lu, Y. C. (2012). Passivity degradation of nuclear steam generator tubing alloy induced by $\mathrm{Pb}$ contamination at high temperature. $J$. Nucl. Mater. 429, 305-314. doi: 10.1016/j.jnucmat.2012.06.021

Macdonald, D. D. (2011). The history of the Point Defect Model for the passive state: a brief review of film growth aspects. Electrochim. Acta 56, 1761-1772. doi: 10.1016/j.electacta.2010.11.005

Marchetti, L., Perrin, S., Raquet, O., and Pijolat, M. (2008). Corrosion mechanisms of Ni-base alloys in pressurized water reactor primary conditions. Mater. Sci. Forum 595-598, 529-537. doi: 10.4028/www.scientific.net/MSF.595-598.529

Meng, F. J., Han, E. H., Wang, J. Q., Zhang, Z. M., and Ke, W. (2011). Localized corrosion behavior of scratches on nickel-base Alloy 690TT. Electrochim. Acta 56, 1781-1785. doi: 10.1016/j.electacta.2010.08.028

Meng, F. J., Wang, J. Q., Han, E. H., and Ke, W. (2009). Effects of scratching on corrosion and stress corrosion cracking of Alloy $690 \mathrm{TT}$ at $58^{\circ} \mathrm{C}$ and $330^{\circ} \mathrm{C}$. Corros. Sci. 51, 2761-2769. doi: 10.1016/j.corsci.2009.07.015

Mischler, S., Mathieu, H. J., and Landolt, D. (2010). Investigation of a passive film on an iron-chromium alloy by AES and XPS. Surf. Interface Anal. 11, 182-188. doi: 10.1002/sia.740110403
Payet, M., Marchetti, L., Tabarant, M., and Chevalier, J. (2015). Corrosion mechanism of a Ni-based alloy in supercritical water: impact of surface plastic deformation. Corrosi. Sci. 100, 47-56. doi: 10.1016/j.corsci.2015.06.032

Peng, B., Lu, B. T., Luo, J. L., Lu, Y. C., and Ma, H. Y. (2008). Investigation of passive films on nickel Alloy 690 in Pb-containing environments. J. Nucl. Mater. 378, 333-340. doi: 10.1016/j.jnucmat.2008.06.037

Persaud, S. Y., Smith, J. M., Judge, C. D., Long, F., Korinek, A., Capell, B., et al. (2018). High resolution characterization of Pb-SCC in Alloy 800 exposed to $330^{\circ} \mathrm{C}$ mildly caustic environments. Corrosi. Sci. 140, 333-348. doi: 10.1016/j.corsci.2018.05.031

Rebak, R. B., and Szklarska-Smialowska, Z. (1996). The mechanism of stress corrosion cracking of alloy 600 in high temperature water. Corrosi. Sci. 38, 971-988. doi: 10.1016/0010-938X(96)00183-7

Schultze, J. W., and Lohrengel, M. M. (2000). Stability, reactivity and breakdown of passive films. Problems of recent and future research. Electrochim. Acta. 45, 2499-2513. doi: 10.1016/S0013-4686(00)00347-9

Sikora, E., Sikora, J., and Macdonald, D. D. (1996). A new method for estimating the diffusivities of vacancies in passive films. Electrochim. Acta 41, 783-789. doi: 10.1016/0013-4686(95)00312-6

Souier, T., Martin, F., Bataillon, C., and Cousty, J. (2010). Local electrical characteristics of passive films formed on stainless steel surfaces by current sensing atomic force microscopy. Appl. Surf. Sci. 256, 2434-2439. doi: 10.1016/j.apsusc.2009.10.083

Staehle, R. W., and Gorman, J. A. (2003). Quantitative assessment of submodes of stress corrosion cracking on the secondary side of steam generator tubing in pressurized water reactors: part 1. Corrosion 59, 931-994. doi: $10.5006 / 1.3277522$

Wang, Z. W., Yan, Y., and Qiao, L. J. (2017). Protein adsorption on implant metals with various deformed surfaces. Colloid. Surface B. 156, 62-70. doi: 10.1016/j.colsurfb.2017.05.015

Zhang, Z. M., Wang, J. Q., Han, E. H., and Ke, W. (2011). Influence of dissolved oxygen on oxide films of Alloy 690TT with different surface status in simulated primary water. Corros. Sci. 53, 3632-3635. doi: 10.1016/j.corsci.2011. 07.012

Zhang, Z. M., Wang, J. Q., Han, E. H., and Ke, W. (2012). Effects of surface state and applied stress on stress corrosion cracking of Alloy 690TT in lead-containing caustic solution. J. Mater. Sci. Technol. 28, 785-792. doi: 10.1016/S1005-0302(12)60131-5

Conflict of Interest: The authors declare that the research was conducted in the absence of any commercial or financial relationships that could be construed as a potential conflict of interest.

Copyright (C) $2019 \mathrm{Li}, \mathrm{He}$, Guo, Li and Qiao. This is an open-access article distributed under the terms of the Creative Commons Attribution License (CC BY). The use, distribution or reproduction in other forums is permitted, provided the original author(s) and the copyright owner(s) are credited and that the original publication in this journal is cited, in accordance with accepted academic practice. No use, distribution or reproduction is permitted which does not comply with these terms. 